\title{
PERAN MEDIASI KEPEMIMPINAN TRANSFORMASIONAL PADA PENGARUH KECERDASAN EMOSIONAL TERHADAP EFEKTIVITAS TIM PT. SURTICON BUANA PERKASA
}

\author{
Ervina Wilyanita ${ }^{1}$ \\ I Gusti Salit Ketut Netra ${ }^{2}$
}

${ }^{1,2}$ Fakultas Ekonomi dan Bisnis Universitas Udayana (Unud), Bali, Indonesia E-mail: ervinna@rocketmail.com

\begin{abstract}
ABSTRAK
Memiliki kecerdasan emosional yang kurang baik serta kurangnya kemampuan pemimpin dalam menerapkan gaya kepemipinan transformasional akan mempengaruhi efektivitas tim kerja suatu perusahaan. Efektivitas tim kerja yang lemah akan berpengaruh pada keberhasilan perusahaan, sehingga berdampak kurang baik bagi kemajuan perusahaan. Penelitian ini bertujuan untuk mengetahui peran kepemimpinan transformasional dalam memediasi pengaruh kecerdasan emosional terhadap efektivitas tim kerja. Penelitian ini dilakukan di PT. Surticon Buana Perkasa Denpasar, dengan jumlah karyawan sebanyak 52 orang. Pengumpulan data dilakukan dengan metode sensus (sampel jenuh) dari hasil penyebaran kuesioner. Analisis data menggunakan uji asumsi klasik, analisis jalur path, uji sobel, dan uji VAF. Berdasarkan hasil analisis ditemukan bahwa kecerdasan emosional berpengaruh positif dan signifikan terhadap kepemimpinan transformasional, kecerdasan emosional berpengaruh positif dan signifikan terhadap efektivitas tim, kepemimpinan transformasional berpengaruh positif dan signifikan terhadap efektivitas tim, dan kecerdasan emosional berpengaruh positif dan signifikan terhadap efektivitas tim melalui mediasi kepemimpinan transformasional.

Kata kunci: kepemimpinan transformasional, kecerdasan emosional, efektivitas tim
\end{abstract}

\section{ABSTRACT}

A poor emotional intelligence and lack of transformational leadership application by the leader will affect company's teamwork effectivity. The weak of teamwork effectivity will affect company's success that will obstruct company improvement. This research aims to determine the role of transformational leadership style in mediating emotional intelligence on teamwork effectivity. This reseachwas conducted at PT. Surticon Buana Perkasa Denpasar, which has 52 employees. Data collection was obtained from questionnairs and analyzed by classical assumption test, pathway analysis, Sobel test, and VAF test. The results showed that emotional intelligence has positive and significant effect on transformational leadership style and teamwork effectivity, transformational leadership style has positive and significant effect on teamwork effectivity, and emotional intelligence has positive and significant effect on teamwork effectivity by transformational leadership style mediated.

Keywords: transformational leadership, emotional intelligence, teamwork effectivity 


\section{PENDAHULUAN}

Sumber daya manusia merupakan tokoh sentral yang berperan agar aktivitas manajemen berjalan dengan baik, sehingga sumber daya manusia dikatakan sangat penting dalam suatu perusahaan karena keberhasilan perusahaan sangat bergantung pada kualitas sumber daya manusianya, baik yang menempati posisi pemimpin maupun bawahan harus memiliki pengetahuan dan keterampilan yang tinggi, serta usaha untuk mengelola perusahaan seoptimal mungkin secara efektif sehingga tercapainya tujuan perusahan tersebut. Keberhasilan perusahaan akan tercapai secara maksimal dilihat dari efektivitas tim kerja perusahaan tersebut. Efektivitas tim merupakan bagaimana tim itu dapat mencapai tujuan yang disepakati sehingga dapat mempengaruhi perusahaan, anggota timnya, serta keberlangsungan tim tersebut (Yarouf Estianda, 2014).

Menurunnya efektivitas tim dalam bekerja dapat ditingkatkan melalui peningkatkan kecerdasan emosional. Kecerdasan emosional merupakan kemampuan untuk merasakan, memahami dan lebih efektif dalam menerapkan daya kepekaan emosi sebagai sumber energi, informasi, koneksi, dan pengaruh yang manusiawi (Goleman, 2015). Kecerdasan emosional bisa menjadikan terciptanya suasana tim kerja yang dinamis dikarenakan semua karyawan bisa mengendalikan segala ego, keinginan, dan memahami karyawan lainnya (Tantriana, 2015). Fikrie Anugrah (2017), Kusnara (2013), Evo Hariandja (2007), Saqib Khan et al. (2014) dan Harminder, K,G \& Jaya, A. (2011) dalam penelitiannya mendapatkan hasil bahwa kecerdasan emosional berpengaruh positif dan signifikan terhadap efektivitas tim kerja. Tetapi berbeda dengan penelitian Y. Hur et al. (2011), hasilnya menunjukkan bahwa kecerdasan emosional tidak berpengaruh positif terhadap efektivitas tim kerja.

Kecerdasan emosional yang baik yang dimiliki oleh para karyawan perusahaan akan dipengaruhi oleh gaya kepemimpinan yang bersifat transparan yaitu kepemimpinan transformasional. Kepemimpinan transformasional memastikan hubungan sosial yang saling menguntungkan dengan bawahan (Yulk, 2006). Pemimpin transformasional mengubah dan memotivasi karyawan untuk meningkatkan kinerjanya.

Pemimpin transformasional sangat dibutuhkan oleh setiap karyawan, dengan kepemimpinan transformasional akan membuat kecerdasan emosional yang dimiliki masing - masing individu dapat terkontrol dengan baik, sehingga dapat meningkatkan efektivitas tim dalam perusahaan. Beberapa peneliti telah menguji hubungan antara kepemimpinan transformasional dengan efektivitas tim, antara lain Melvyn Lopez (2015), Amin Akhavan Tabassi (2013), Wahba (2016), Y.Hur et al. (2011) telah menunjukkan bahwa kepemimpinan transformasional berpengaruh positif terhadap efektivitas tim.

PT. Surticon Buana Perkasa merupakan perusahaan yang bergerak di pendistribusian produk semen gresik terbesar di Bali, yang memiliki 6 gudang tersebar di kota - kota besar di Bali, memiliki total karyawan sebanyak 52 orang. Berdasarkan hasil penyebaran kuisioner pra survey yang berdasarkan indikator efektivitas tim kerja karyawan yang dilakukan terhadap 10 karyawan PT. Surticon 
Buana Perkasa, terjadi permasalahan yang mengindikasikan rendahnya efektivitas tim kerja karyawan. Hal ini dapat dilihat pada Tabel 1.

Tabel 1.

Kuisioner Pra Survey Tentang Efektivitas Tim Kerja Karyawan PT. Surticon Buana Perkasa Tahun 2018

\begin{tabular}{|c|c|c|c|c|c|c|}
\hline No. & Pertanyaan & SS & $\mathbf{S}$ & $\mathbf{N}$ & TS & STS \\
\hline 1. & $\begin{array}{l}\text { Tim saya output produktifnya dapat memenuhi } \\
\text { harapan pelanggan. }\end{array}$ & 0 & 2 & 3 & 5 & 0 \\
\hline 2. & $\begin{array}{l}\text { Tim saya dapat bersosialisasi dengan baik untuk } \\
\text { bekerja sama menyelesaikan pekerjaan. }\end{array}$ & 0 & 3 & 3 & 4 & 0 \\
\hline 3. & $\begin{array}{l}\text { Tim saya berkontribusi positif terhadap } \\
\text { kesejahteraan anggota tim. }\end{array}$ & 0 & 1 & 2 & 5 & 2 \\
\hline & Jumlah & $\mathbf{0}$ & 6 & 8 & 14 & 2 \\
\hline
\end{tabular}

Tabel 1. menunjukkan bahwa ada beberapa karyawan yang mengindikasikan masih kurangnya efektivitas tim kerja karyawan PT. Surticon Buana Perkasa di Denpasar. Terlihat dari jawaban responden yang lebih banyak menjawab sangat tidak setuju dan tidak setuju dibandingkan dengan setuju dan sangat setuju. Berdasarkan data tersebut, dapat diketahui bahwa output produktif tim kerja PT. Surticon Buana Perkasa tidak dapat menyelesaikan pekerjaan dengan baik sesuai harapan pelanggan terlihat dari banyaknya responden yang menjawab tidak setuju sebanyak 5 orang. Tim kerja PT. Surticon Buana Perkasa juga tidak dapat bersosialisasi dengan baik untuk bekerja sama menyelesaikan pekerjaan terlihat dari banyaknya respoden yang menjawab tidak setuju sebanyak 4 orang. Selain itu tim kerja PT. Surticon Buana Perkasa tidak berkontribusi positif terhadap kesejahteraan anggota tim terlihat dari sebanyak 5 orang yang menjawab tidak setuju dan 2 orang yang menjawab tidak setuju. Maka dari itu penelitian ini dilakukan untuk mengetahui menyebab hal ini.

Berdasarkan wawancara yang dilakukan dengan pemimpin mengenai hal efektivitas tim dan kecerdasan emosional, pemimpin menjelaskan bahwa adanya suatu masalah seperti pernah terjadi perdebatan antar karyawan satu dengan karyawan lainnya dan karyawan yang ditugaskan satu tim kerja kadang tidak dapat menyelesaikan tugasnya tepat waktu sesuai dengan target yang telah ditetapkan. Selain hal tersebut berdasarkan hasil wawancara yang dilakukan dengan beberapa karyawan mengenai kepemimpinan, karyawan menjelaskan bahwa pemimpin kurang tegas sehingga tidak dapat mempengaruhi para bawahannya untuk bekerja lebih efektif dan efisian dalam menyelesaikan suatu tugas.

Penelitian ini memiiki tujuan untuk mengetahui pengaruh kecerdasan emosional terhadap efektivitas tim, mengetahui pengaruh kecerdasan emosional terhadap kepemimpinan transformasional, mengetahui pengaruh kepemimpinan transformasional terhadap efektivitas tim dan untuk mengetahui kepemimpinan transformasional memediasi pengaruh kecerdasan emosional terhadap efektivitas tim. 


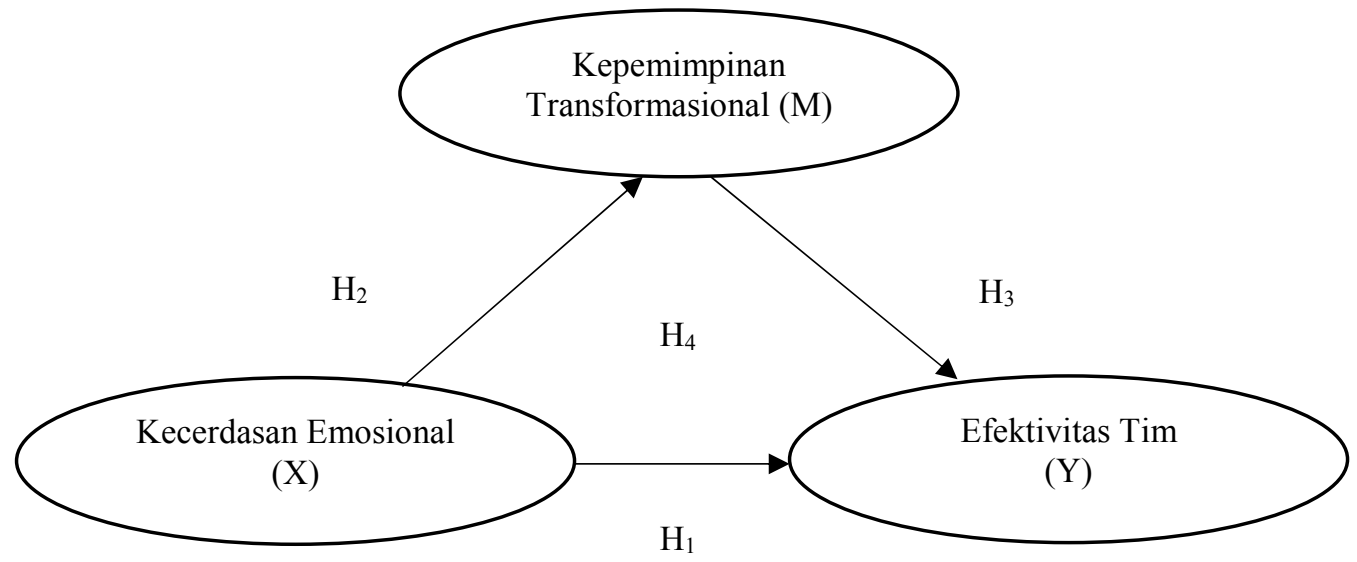

\section{Gambar 1. Kerangka Penelitian}

Penelitian ini menggunakan teori kepemimpinan transformasional Bass karena teori ini sudah mencangkup semua variabel - variabel yang ada dalam penelitian ini, terutama pada variabel mediasi yang digunakan yaitu kepemimpinan transformasional, dimana kepemimpinan transformasional dapat memberi pengaruh idealis, memberikan motovasi yang mengispirasi, memberikan dorangan untuk menjadi inovatif dan kreatif, dan dapat memberikan perhatian khusus terhadap kebutuhan masing-masing bawahannya untuk pencapaian kecerdasan emosional yang tinggi sehingga mampu menciptakan keefektifan tim kerja dalam suatu perusahaan.

Efektivitas tim kerja merupakan tim dapat berkomitmen akan keberhasilan perusahaan, sehingga dapat saling berbagi nilai terkait kualitas, keamanan maupun kepuasan pelanggan, dan saling bertanggung jawab untuk menyelesaikannya (Wageman, Hackman, dan Lehman, 2005). Mac Shane dan Van Glonov (2008), keeefektifan tim adalah perluasan dimana tim memperoleh tujuannya, memperoleh kebutuhan dan tujuan anggotanya, yang dapat mempertahankan timnya lebih lama. Keefektifan tim adalah sebuah tim yang dapat meraih tujuannya dengan tepat, karena setiap individu diciptakan untuk menjadi pemain tim sehingga dapat berfungsi dalam suatu keterkaitan atau hubungan yang saling bergantungan satu sama lain (Heristi dan Seger, 2011). Yarouf Estianda (2014), efektivitas tim merupakan bagaimana tim itu dapat mencapai tujuan yang disepakati sehingga dapat mempengaruhi perusahaan, anggota timnya, serta keberlangsungan tim tersebut.

Wageman, Hackman, dan Lehman (2005), menyatakan bahwa ada tiga indikator untuk mengukur efektivitas tim kerja yaitu: 1) Output produktif dari tim yaitu produk, layanan, atau keputusannya memenuhi atau melampaui standar kuantitas, kualitas, serta ketepatan waktu dari apa yang diharapkan pelanggan. 2) Proses sosialisasi dalam tim yaitu proses sosial yang digunakan tim dalam melaksanakan pekerjaan dalam meningkatkan kemampuan anggota tim untuk bekerja sama. 3) Pengalaman tim yaitu pengalaman kelompok berkontribusi positif terhadap pembelajaran dan kesejahteraan anggota tim per individu. 
Zaccaro (2001) mendefinisikan kecerdasan emosional sebagai kekuatan penerimaan logis dan memahami serangkaian emosi dan percaya bahwa manajer yang memiliki kecerdasan sosial yang tinggi, dengan bantuan kepercayaan diri dan pusat kendali internal yang optimal memiliki kemampuan yang tinggi untuk mengidentifikasi kebutuhan eksekutif manajemen yang berpengaruh, seperti fleksibilitas, manajemen konflik dan pengaturan dan pelacakan tujuan jangka panjang dan membuka dasar untuk mengoptimalkan organisasi di masyarakat. Rendahnya kecerdasan emosional yang dimiliki oleh karyawan dapat dilihat dari kurangnya karyawan dalam mengendalikan emosi, karyawan kurang mampu mengenal orang lain secara baik, karyawan kurang mampu memotivasi diri sendiri, serta karyawan kurang mampu menjaga hubungan antara pimpinan maupun hubungan sesama karyawan (Ratna Murida, 2013).

Menurut teori Salovey \& Mayer (2006) kecerdasan emosional dapat dinilai dari lima indikator yaitu : 1) Self awareness (mengenali emosi diri). Suatu kemampuan untuk memahami apa yang kita rasakan pada suatu situasi untuk memandu pengambilan keputusan diri sendiri. 2) Self regulation (mengelola emosi). Suatu kemampuan untuk mengendalikan emosi kita sehingga dapat berdampak positif kepada pelaksanaan tugas. 3) Motivation (memotivasi diri). Suatu kemampuan untuk selalu optimis dalam menuntun kita menuju sasaran karir. 4) Empathy (memahami emosi orang lain). Suatu kemampuan untuk mengerti apa yang dirasakan oleh orang lain. 5) Social skill (keterampilan sosial). Suatu kemampuan untuk menangani emosi dengan baik dalam menjalin hubungan kerja sama dalam suatu tim.

Dewi dan Mujiati (2015) menyatakan bahwa gaya kepemimpinan transformasional merupakan pemimpin dengan sosok yang visioner, inspiratif, meningkatkan kinerja, serta bertindak sebagai pemimpin yang efektif. Jeevan Jyoti (2015) mengemukakan bahwa pemimpin transformasional memiliki pengetahuan, dinamis dan proaktif dan mampu memimpin diri mereka sendiri dan bawahan mereka atau sebagai penggerak utama kreativitas karyawan dan sangat memengaruhi hasil bisnis, seperti efisiensi, efektivitas, kinerja, kesuksesan, kelangsungan hidup, dan keberlanjutan. Ljungholm Doina (2014) mengemukakan bahwa kepemimpinan transformasional mensyaratkan perilaku kepemimpinan yang luar biasa yang menginspirasi dan mengembangkan pengikut, dan pemimpin transformasional fokus pada mengkomunikasikan serangkaian nilai yang jelas kepada pengikut mereka. Umme Salma Sultana (2015) mengemukakan bahwa gaya kepemimpinan transformasional adalah seorang pemimpin sejati yang memiliki kemampuan untuk memurnikan etika, kepercayaan, dan persyaratan pengikut menjadi sebuah visi, dan kemudian membimbing mereka untuk mengejar visi itu.

Gunawan dan Netra (2017) menyatakan kepemimpinan transformasional cenderung memberi perhatian lebih kepada para pengikutnya. Darto, (2013) berpendapat bahwa pemimpin transformasional memotivasi bahwa untuk berbuat lebih dari apa yang sesungguhnya diharapkan yaitu dengan mengikat arti penting dan nilai tugas di mata bawahan, dengan mendorong bawahan mengorbankan kepentingan tim, organisasi, atau kebijakan yang lebih besar dan dengan menaikkan tingkat kebutuhannya ke taraf yang lebih tinggi. 
Indikator yang mempengaruhi variabel kepemimpinan transformasional (Bass, 1985:49) yaitu: 1) Pengaruh idealis, pemimpin transformasional berprilaku dengan cara mempengaruhi pengikut mereka bahwa pemimpin memiliki pendirian yang kuat dan komitmen dalam memimpin perusahaan. 2) Motivasi inspirasional, pemimpin transformasional berprilaku dengan memberikan motivasi atau dorongan yang menarik terhadap apa yang perlu dilakukan oleh pengikutnya. 3) Stimulasi intelektual, pemimpin transformasional memberi inspirasi bawahannya untuk lebih kreatif dan inovatif mengeluarkan ide - idenya dalam menyelesaian permasalahan yang ada. 4) Pertimbangan individu, pemimpin transformasional memberikan perhatian khusus terhadap kebutuhan masingmasing pengikut untuk lebih berkembang dan berprestasi dengan bertindak sebagai pelatih atau mentor.

Fikrie Anugrah (2017), Kusnara (2013), Evo Hariandja (2007), Saqib Khan et al. (2014) dan Harminder, K,G \& Jaya, A. (2011) dalam penelitiannya mendapatkan hasil bahwa kecerdasan emosional berpengaruh positif dan signifikan terhadap efektivitas tim kerja. Rumusan hipotesis penelitian dari beberapa sumber di atas dapat dinyatakan sebagai berikut.

$\mathrm{H}_{1}$ : kecerdasan emosional berpengaruh positif dan signifikan terhadap efektivitas tim.

Hasil penelitian Mula (2013), Y.Hur et al. (2011), Shahram Alam (2014) dan Nooshin Esfahani, et al. (2011) menyatakan bahwa kecerdasan emosional berpengaruh positif dan signifikan terhadap perilaku kepemimpinan transformasional. Rumusan hipotesis penelitian dari beberapa sumber di atas dapat dinyatakan sebagai berikut.

$\mathrm{H}_{2}$ : kecerdasan emosional berpengaruh positif dan signifikan terhadap kepemiminan tranformasional.

Hasil penelitian Melvyn Lopez (2015), Amin Akhavan Tabassi (2013), Wahba (2016), Y.Hur et al. (2011) menyatakan kepemimpinan transformasional berpengaruh positif dan signifikan terhadap efektivitas tim. Rumusan hipotesis penelitian dari beberapa sumber di atas dapat dinyatakan sebagai berikut.

$\mathrm{H}_{3}$ : kepemimpinan transformasional berpengaruh positif dan signifikan terhadap efektivitas tim.

Cheok San Lam \& Elenor O'Higgins (2015), Joni Christian Vierimaa (2013), Prati et al. (2003) dan Schlechter (2008) menyatakan bahwa kepemimpinan transformasional menjadi pemediasi hubungan antara kecerdasan emosional terhadap efektivitas tim. Rumusan hipotesis penelitian dari beberapa sumber di atas dapat dinyatakan sebagai berikut.

$\mathrm{H}_{4}$ : kepemimpinan transformasional mampu memediasi pengaruh kecerdasan emosional terhadap efektivitas tim.

\section{METODE PENELITIAN}

Penelitian ini menggunakan desain penelitian asosiatif, yaitu menganalisis peran kepemimpinan transformasional dalam memediasi pengaruh kecerdasan emosional terhadap efektivitas tim kerja karyawan, serta menguji suatu hipotesis dengan kuesioner sebagai instrumen penelitian yang dipakai. Penelitian ini dilakukan di PT. Surticon Buana Perkasa berletak di Jalan Raya Cargo No. 298, 
Denpasar Barat - Bali, 80116, Indonesia. Objek dalam penelitian ini adalah kecerdasan emosional, kepemimpinan transfomasional, dan efektivitas tim.

Populasi dari penelitian ini adalah seluruh karyawan di PT. Surticon Buana Perkasa yang berjumlah 52 karyawan. Penelitian ini menggunakan metode sampel jenuh, yaitu seluruh karyawan sebanyak 52 orang karyawan dipilih menjadi sampel diluar pemimpin perusahaan atau direktur PT. Surticon Buana Perkasa.

Jenis data yang digunakan dalam penelitian ini ada 2 yaitu data kuantitatif adalah hasil pembobotan jawaban responden terhadap kuisioner dan data kualitatifnya berupa pernyataan-pernyataan yang diajukan dalam kuisioner.

Instrumen dalam penelitian ini adalah keuisioner, untuk mengetahui apakah kuisioner sudah tepat dan layak untuk dijadikan instrumen penelitian maka dilakukan uji validitas dan uji reliabilitas terlebih dahulu. Uji validitas dilakukan untuk mengetahui apakah kuisioner sudah tepat untuk mengukur indikator dalam penelitian. Pengujian reliabilitas instrumen merupakan syarat pengujian validitas instrument yang harus dilakukan karena instrumen yang valid pada umumnya reliable, akan tetapi pengujian reliabilitas instrumen tetap dilakukan untuk mencari tau sejauh mana konsistensi alat ukur yang digunakan, sehingga bila alat ukur tersebut digunakan kembali untuk meneliti objek yang sama walaupun waktunya berbeda, maka hasil yang diperoleh akan sama (Sugiyono, 2017).

Teknik analisis yang digunakan pada penelitian ini berupa uji asumsi klasik yaitu uji normalitas, uji heteroskedastisitas, dan uji multikolinieritas, serta berupa teknik analisis jalur (path analysis) yang merupakan peluasan dari analisis regresi linier berganda dalam memperkirakan hubungan kausalitas antara variabel yang telah ditetapkan sebelumnya berdasarkan teori (Ghozali, 2013 : 249). Setelah melakukan teknik path analysis, maka dilakukan uji sobel dengan tujuan menguji signifikansi kepemimpinan transformasional sebagai variabel mediator dalam hubungan antara variabel kecerdasan emosional dan variabel efektivitas tim kerja. Terakhir melakukan uji VAF yaitu ukuran seberapa variabel pemediasi mampu menyerap pengaruh langsung yang sebelumnya signifikan dari model tanpa pemediasi.

\section{HASIL DAN PEMBAHASAN}

Berdasarkan kuisioner penelitian yang berjumlah 52 orang tersebut, maka proporsi karakteristik responden yang didapat yaitu:

\section{Tabel 2.}

Karakteristik Responden Berdasarkan Jenis Kelamin PT. Surticon Buana Perkasa

\begin{tabular}{cccc}
\hline No & Jenis Kelamin & Jumlah Orang & Persentase (\%) \\
\hline 1. & Laki-Laki & 40 & 76,9 \\
2. & Perempuan & 12 & 23,1 \\
& Total & $\mathbf{5 2}$ & $\mathbf{1 0 0}$ \\
\hline
\end{tabular}

Sumber: Data primer diolah, 2018.

Tabel 2. menunjukkan bahwa sebagian besar responden adalah laki-laki dilihat dari nilai persentasenya lebih besar dibandingkan perempuan yaitu sebesar 
76,9 persen. Artinya sebagian besar karyawan PT. Surticon Buana Perkasa mempekerjakan tenaga laki-laki.

Tabel 3.

Karakteristik Responden Berdasarkan Usia di PT. Surticon Buana Perkasa

\begin{tabular}{cccc}
\hline No & Usia & Jumlah Orang & Persentase (\%) \\
\hline 1 & $21-$ 30 Tahun & 28 & 53,85 \\
2 & 31 - 40 Tahun & 11 & 21,15 \\
3 & 41 - 50 Tahun & 8 & 15,38 \\
4 & 51 - 60 Tahun & 5 & 9,62 \\
& Total & $\mathbf{5 2}$ & $\mathbf{1 0 0}$ \\
\hline
\end{tabular}

Sumber: Data primer diolah, 2018.

Tabel 3. menunjukkan persentase terbesar yaitu 53,85 persen yang terdapat pada responden yang berusia 21-30 tahun, artinya bahwa karyawan PT. Surticon Buana Perkasa didominasi oleh usia 21-30 tahun dikarenakan usia tersebut adalah usia yang tergolong masih muda dan berpeluang mengembangkan karir yang lebih baik lagi. Dengan demikian dapat disimpulkan karyawan PT. Surticon Buana Perkasa berada pada usia produktif.

Tabel 4.

Karakteristik Responden Berdasarkan Pendidikan Terakhir di PT. Surticon Buana Perkasa

\begin{tabular}{cccc}
\hline No & Pendidikan & Jumlah Orang & Persentase (\%) \\
\hline 1 & SMA & 12 & 23,08 \\
2 & DIPLOMA & 23 & 44,23 \\
3 & S1 & 16 & 30,77 \\
4 & S2 & 1 & 1,92 \\
& Total & $\mathbf{5 2}$ & $\mathbf{1 0 0}$ \\
\hline
\end{tabular}

Sumber: Data primer diolah, 2018.

Tabel 4. menunjukkan bahwa persentase terbesar yaitu 44,23 persen yang terdapat pada responden dengan pendidikan terakhir Diploma, artinya bahwa karyawan PT. Surticon Buana Perkasa didominasi oleh pendidikan terakhir Diploma.

Tabel 5.

Karakteristik Responden Berdasarkan Lama Bekerja Karyawan di PT. Surticon Buana Perkasa

\begin{tabular}{cccc}
\hline No & Masa Kerja & Jumlah Orang & Persentase \%) \\
\hline 1 & 1-3 Tahun & 17 & 32,69 \\
2 & 4-6 Tahun & 23 & 44,23 \\
3 & 7-9 Tahun & 12 & 23,08 \\
& Total & $\mathbf{5 2}$ & $\mathbf{1 0 0}$ \\
\hline
\end{tabular}

Sumber: Data primer diolah, 2018.

Tabel 5. menunjukkan bahwa masa kerja responden selama 4-6 tahun memiliki persentase tertinggi sebesar 44,23 persen, yang dapat diartikan bahwa masa kerja karyawan PT. Surticon Buana Perkasa didominasi oleh responden dengan masa kerja selama 4-6 tahun dengan pengalaman kerja yang sudah baik. 
Tabel 6.

Hasil Uji Validitas Instrumen Penelitian

\begin{tabular}{|c|c|c|c|}
\hline Variabel & Instrumen & Koefisien Korelasi & Keterangan \\
\hline \multirow{3}{*}{ Efektivitas Tim (Y) } & $\mathrm{Y}_{1}$ & 0,864 & Valid \\
\hline & $\mathrm{Y}_{2}$ & 0,846 & Valid \\
\hline & $\mathrm{Y}_{3}$ & 0,727 & Valid \\
\hline \multirow{5}{*}{$\begin{array}{l}\text { Kecerdasan } \\
\text { Emosional (X) }\end{array}$} & $\mathrm{X}_{1}$ & 0,814 & Valid \\
\hline & $\mathrm{X}_{2}$ & 0,767 & Valid \\
\hline & $\mathrm{X}_{3}$ & 0,888 & Valid \\
\hline & $\mathrm{X}_{4}$ & 0,782 & Valid \\
\hline & $\mathrm{X}_{5}$ & 0,873 & Valid \\
\hline \multirow{4}{*}{$\begin{array}{l}\text { Kepemimpinan } \\
\text { Transformasional (M) }\end{array}$} & $\mathrm{M}_{1}$ & 0,878 & Valid \\
\hline & $\mathrm{M}_{2}$ & 0,783 & Valid \\
\hline & $\mathrm{M}_{3}$ & 0,747 & Valid \\
\hline & $\mathrm{M}_{4}$ & 0,821 & Valid \\
\hline
\end{tabular}

Sumber: Data primer diolah, 2018.

Uji validitas pada Tabel 6. menunjukkan seluruh indikator dalam variabel variabel tersebut memiliki nilai koefisien korelasi yang lebih besar dari 0,3 sehingga butir-butir pernyataan tersebut dikatakan valid dan layak digunakan sebagai instrumen penelitian.

Tabel 7.

Hasil Uji Reliabilitas

\begin{tabular}{lcc}
\hline \multicolumn{1}{c}{ Variabel } & Alpha Cronbach & Keterangan \\
\hline Efektivitas Tim (Y) & 0,732 & Reliabel \\
Kecerdasan Emosional (X) & 0,879 & Reliabel \\
Kepemimpinan Transformasional (M) & 0,822 & Reliabel \\
\hline
\end{tabular}

Sumber: Data primer diolah, 2018.

Uji reliabilitas pada Tabel 7. menunjukkan nilai koefisien alpha cronbach seluruh variabel penelitian sudah lebih besar dari 0,6 yang berarti telah memenuhi syarat reliabilitas atau kehandalan sehingga dapat digunakan untuk melakukan penelitian.

Tabel 8.

Deskripsi Jawaban Responden Mengenai Variabel Efektivitas Tim

\begin{tabular}{|c|c|c|c|c|c|c|c|c|}
\hline \multirow[t]{2}{*}{ Pernyataan Efektivitas Tim } & \multicolumn{5}{|c|}{$\begin{array}{c}\text { Frekuensi Jawaban } \\
\text { Responden }\end{array}$} & \multirow{2}{*}{$\begin{array}{l}\text { Total } \\
\text { skor }\end{array}$} & \multirow{2}{*}{$\begin{array}{l}\text { Rata- } \\
\text { rata }\end{array}$} & \multirow[t]{2}{*}{ Ket } \\
\hline & 1 & 2 & 3 & 4 & 5 & & & \\
\hline $\begin{array}{l}\text { Tim saya output produktifnya dapat } \\
\text { memenuhi harapan pelanggan. }\end{array}$ & 0 & 0 & 8 & 25 & 19 & 219 & 4.21 & $\begin{array}{c}\text { Sangat } \\
\text { Baik }\end{array}$ \\
\hline $\begin{array}{l}\text { Tim saya dapat bersosialisasi dengan baik } \\
\text { untuk bekerja sama menyelesaikan } \\
\text { pekerjaan. }\end{array}$ & 0 & 0 & 15 & 22 & 15 & 208 & 4.00 & Baik \\
\hline $\begin{array}{l}\text { Tim saya berkontribusi positif terhadap } \\
\text { kesejahteraan anggota tim. }\end{array}$ & 0 & 1 & 10 & 23 & 18 & 214 & 4.12 & Baik \\
\hline \multicolumn{7}{|l|}{ Rata-rata } & 4,11 & Baik \\
\hline
\end{tabular}


Penilaian responden terhadap variabel efektivitas tim kerja karyawan ditunjukan pada Tabel 8. sebesar 4,11 yang digolongkan dengan kriteria baik, artinya pada instrumen variabel efektivitas tim dapat dikatakan bahwa karyawan PT. Surticon Buana Perkasa rata-rata telah merasakan efektivitas tim kerja yang baik.

Tabel 9.

Deskripsi Jawaban Responden Mengenai Variabel Kecerdasan Emosional

\begin{tabular}{|c|c|c|c|c|c|c|c|c|}
\hline \multirow[t]{2}{*}{ Pernyataan Kecerdasan Emosional } & \multicolumn{5}{|c|}{$\begin{array}{l}\text { Frekuensi Jawaban } \\
\text { Responden }\end{array}$} & \multirow[t]{2}{*}{$\begin{array}{l}\text { Total } \\
\text { skor }\end{array}$} & \multirow[t]{2}{*}{$\begin{array}{l}\text { Rata- } \\
\text { rata }\end{array}$} & \multirow[t]{2}{*}{ Ket } \\
\hline & 1 & 2 & 3 & 4 & 5 & & & \\
\hline $\begin{array}{l}\text { Saya dapat memahami emosi yang } \\
\text { terjadi pada diri saya. }\end{array}$ & 0 & 0 & 11 & 26 & 15 & 212 & 4.08 & Baik \\
\hline $\begin{array}{l}\text { Saya mampu mengendalikan emosi } \\
\text { diri sendiri. }\end{array}$ & 0 & 0 & 17 & 24 & 11 & 202 & 3.88 & Baik \\
\hline $\begin{array}{l}\text { Saya dapat memotivasi diri saya } \\
\text { sendiri dalam mencapai sasaran karir. }\end{array}$ & 0 & 0 & 14 & 27 & 11 & 205 & 3.94 & Baik \\
\hline Saya dapat mengerti emosi orang lain. & 0 & 0 & 14 & 28 & 10 & 204 & 3.92 & Baik \\
\hline $\begin{array}{l}\text { Saya memilik1 ketrampilan sosial } \\
\text { dalam menjalin hubungan kerja sama } \\
\text { dengan baik. }\end{array}$ & 0 & 0 & 16 & 28 & 8 & 200 & 3.85 & Baik \\
\hline \multicolumn{7}{|c|}{ Rata-rata } & 3,93 & Baik \\
\hline
\end{tabular}

Sumber : Data primer diolah, 2018.

Penilaian responden terhadap variabel kecerdasan emosional ditunjukan pada Tabel 9. sebesar 3,93 yang digolongkan pada kriteria baik, artinya karyawan karyawan PT. Surticon Buana Perkasa sudah memiliki kecerdasan emosional yang baik.

Tabel 10.

Deskripsi Jawaban Responden Mengenai Variabel Kepemimpinan Transformasional

\begin{tabular}{|c|c|c|c|c|c|c|c|c|}
\hline \\
\hline \multirow{2}{*}{$\begin{array}{l}\text { Pernyataan Kepemimpinan } \\
\text { Transformasional }\end{array}$} & \multicolumn{5}{|c|}{$\begin{array}{c}\text { Frekuensi Jawaban } \\
\text { Responden }\end{array}$} & \multirow{2}{*}{$\begin{array}{l}\text { Total } \\
\text { skor }\end{array}$} & \multirow{2}{*}{$\begin{array}{l}\text { Rata- } \\
\text { rata }\end{array}$} & \multirow[t]{2}{*}{ Ket } \\
\hline & 1 & 2 & 3 & 4 & 5 & & & \\
\hline $\begin{array}{l}\text { Pemimpin mampu memberikan } \\
\text { pengaruh idialisme membuat saya } \\
\text { merasa bangga dengan pendirian } \\
\text { yang kuat. }\end{array}$ & 0 & 0 & 10 & 30 & 12 & 210 & 4.04 & Baik \\
\hline $\begin{array}{l}\text { Pemimpin memberikan saya } \\
\text { motivasi inspirasional dengan } \\
\text { dorongan semangat dalam bekerja. }\end{array}$ & 0 & 1 & 7 & 31 & 13 & 212 & 4.08 & Baik \\
\hline $\begin{array}{l}\text { Pemimpin memberikan stimulasi } \\
\text { intelektual kesempatan kepada } \\
\text { saya untuk memberikan idea atau } \\
\text { masukan untuk perusahaan. }\end{array}$ & 0 & 0 & 9 & 26 & 17 & 216 & 4.15 & Baik \\
\hline $\begin{array}{l}\text { Pimpinan mengajarkan } \\
\text { pertimbangan individual untuk } \\
\text { lebih berkembang dan berprestasi. }\end{array}$ & 0 & 0 & 12 & 29 & 11 & 207 & 3.98 & Baik \\
\hline \multicolumn{7}{|c|}{ Rata-rata } & 4,06 & Baik \\
\hline
\end{tabular}

Sumber: Data primer diolah, 2018. 
Penilaian responden terhadap variabel kepemimpinan transformasional yang ditunjukkan pada Tabel 10. sebesar 4,06 yang digolongkan pada kriteria baik, artinya pada instrumen variabel kepemimpinan transformasional dapat disimpulkan bahwa karyawan PT. Surticon Buana Perkasa telah merasakan gaya kepemimpinan transformasional dengan baik.

Tabel 11.

Hasil Uji Normalitas Struktur I

\begin{tabular}{lc}
\hline & Unstandardized Residual \\
\hline $\mathrm{N}$ & 52 \\
Kolmogorov-Smirnov $Z$ & 0,656 \\
Asymp. Sig. (2-tailed) & 0,782 \\
\hline
\end{tabular}

Sumber: Data primer diolah, 2018.

Hasil analisis data menggunakan uji asumsi klasik yaitu hasil uji normalitas pada Tabel 11. diperoleh hasil nilai signifikansi struktur I (M) yaitu 0,782 lebih dari 0,05 yang berarti data dalam penelitian ini telah berdistribusi normal atau merata.

Tabel 12.

Hasil Uji Normalitas Struktur II

\begin{tabular}{lc}
\hline & Unstandardized Residual \\
\hline $\mathrm{N}$ & 52 \\
Kolmogorov-Smirnov $Z$ & 1,034 \\
Asymp. Sig. (2-tailed) & 0,236 \\
\hline
\end{tabular}

Sumber: Data primer diolah, 2018.

Pada Tabel 12. diperoleh hasil nilai signifikansi struktur II (Y) sebesar 0,236 $>0,05$ yang artinya data berdistribusi normal atau merata.

Tabel 13.

Hasil Uji Heteroskedastisitas Struktur I

\begin{tabular}{|c|c|c|c|c|c|}
\hline \multirow{2}{*}{ Model } & \multicolumn{2}{|c|}{$\begin{array}{l}\text { Unstandardized } \\
\text { Coefficients }\end{array}$} & \multirow{2}{*}{$\begin{array}{c}\begin{array}{c}\text { Standardized } \\
\text { Coefficients }\end{array} \\
\text { Beta }\end{array}$} & \multirow{2}{*}{$\mathbf{T}$} & \multirow{2}{*}{ Sig. } \\
\hline & B & $\begin{array}{c}\text { Std. } \\
\text { Error }\end{array}$ & & & \\
\hline (Constant) & 0,497 & 0,754 & & $-0,658$ & 0,513 \\
\hline $\begin{array}{l}\text { Kecerdasan } \\
\text { emosional }\end{array}$ & 0,023 & 0,038 & 0,087 & 0,615 & 0,541 \\
\hline
\end{tabular}

Sumber: Data primer diolah, 2018.

Uji hesteroskedastisitas pada Tabel 13. menunjukkan bahwa nilai Sig. dari variabel kecerdasan emosional sebesar 0,541 lebih dari 0,05 yang berarti model yang dibuat tidak mengandung gangguan gejala heteroskedastisitas. 
Tabel 14.

Hasil Uji Heteroskedastisitas Struktur II

\begin{tabular}{|c|c|c|c|c|c|}
\hline \multirow{2}{*}{ Model } & \multicolumn{2}{|c|}{$\begin{array}{l}\text { Unstandardized } \\
\text { Coefficients }\end{array}$} & \multirow{2}{*}{$\begin{array}{c}\begin{array}{c}\text { Standardized } \\
\text { Coefficients }\end{array} \\
\text { Beta }\end{array}$} & \multirow{2}{*}{$\mathbf{T}$} & \multirow{2}{*}{ Sig. } \\
\hline & B & $\begin{array}{c}\text { Std. } \\
\text { Error }\end{array}$ & & & \\
\hline (Constant) & 0,182 & 0,711 & & 0,256 & 0,799 \\
\hline $\begin{array}{l}\text { Kecerdasan } \\
\text { emosional }\end{array}$ & 0,106 & 0,060 & 0,441 & 1,781 & 0,081 \\
\hline $\begin{array}{l}\text { Kepemimpinan } \\
\text { Transformasional }\end{array}$ & $-0,098$ & 0,076 & $-0,320$ & $-1,292$ & 0,203 \\
\hline
\end{tabular}

Sumber: Data primer diolah, 2018.

Pada Tabel 14. didapatkan hasil nilai Sig. pada variabel kecerdasan emosional sebesar 0,081 dan kepemimpinan transformasional yaitu 0,203 semuanya lebih besar dari 0,05 yang berarti model yang dibuat tidak mengandung gejala heteroskedastisitas.

Tabel 15.

Hasil Uji Multikolinearitas Struktur I

\begin{tabular}{ccc}
\hline \multirow{2}{*}{ Model } & \multicolumn{2}{c}{ Colinearity Statistic } \\
\cline { 2 - 3 } & Tolerance & VIF \\
\hline Kecerdasan emosional & 1,000 & 1,000 \\
\hline
\end{tabular}

Sumber: Data primer diolah, 2018.

Uji multikoleniaritas pada Tabel 15. menunjukkan nilai koefisien Tolerance dari variabel kecerdasan emosional sebesar 1,000 lebih dari 0,10 dan nilai VIF sebesar 1,000 kurang dari 10. Hasil ini berarti menunjukkan tidak terdapat gejala multikolinear antar variabel dalam model regresi

Tabel 16.

Hasil Uji Multikolinearitas Struktur II

\begin{tabular}{lcc}
\hline \multirow{2}{*}{ Model } & \multicolumn{2}{c}{ Colinearity Statistic } \\
\cline { 2 - 3 } & Tolerance & VIF \\
\hline Kecerdasan emosional & 0,312 & 3,207 \\
Kepemimpinan & 0,312 & 3,207 \\
transformasional & &
\end{tabular}

Sumber: Data primer diolah, 2018.

Pada Tabel 16. menunjukkan bahwa kedua variabel kecerdasan emosional dan kepemimpinan transformasional nilai koefisien Tolerance sebesar lebih dari 0,10 dan nilai VIF kurang dari 10. Hasil ini berarti bahwa tidak terdapat gejala multikolinear antar variabel dari model regresi yang dibuat.

Perhitungan koefisien path Analysis dilakukan dengan analisis regresi melalui software SPSS 22.0 for Windows. Hasil analisis jalur disajikan pada Tabel 17. dan tabel Tabel 18. 
Tabel 17.

Hasil Analisis Jalur Persamaan Regresi 1

\begin{tabular}{cccc}
\hline Model & $\boldsymbol{R}$ Square & $\begin{array}{c}\text { Standardized Coeffcients } \\
\text { Beta }\end{array}$ & Sig. \\
\hline Kecerdasan Emosional & 0,688 & 0,830 & 0,000 \\
\hline
\end{tabular}

Sumber: Data primer diolah, 2018.

Berdasarkan Tabel 17. didapatkan hasil persamaan struktural pada regresi pertama yaitu:

$\mathrm{M}=0,830 \mathrm{X}+\mathrm{e}_{1}$

Tabel 18.

Hasil Analisis Jalur Persamaan Regresi 2

\begin{tabular}{lccc}
\hline \multicolumn{1}{c}{ Model } & $\boldsymbol{R}$ Square & $\begin{array}{c}\text { Standardized Coeffcients } \\
\text { Beta }\end{array}$ & Sig. \\
\hline Kecerdasan Emosional & 0,720 & 0,504 & 0,000 \\
Kepemimpinan & 0,720 & 0,383 & 0,000 \\
Transformasional & & &
\end{tabular}

Sumber: Data primer diolah, 2018.

Berdasarkan Tabel 18. didapatkan hasil persamaan struktural pada regresi kedua yaitu:

$\mathrm{Y}=0,504 \mathrm{X}+0,383 \mathrm{M}+\mathrm{e}_{2}$

Pada persamaan regresi 1 dan regresi 2, telah didapat nilai standar eror $\left(\mathrm{Pe}_{\mathrm{i}}\right)$, didapatkan hasil $\mathrm{Pe}_{1}$ sebesar 0,312 dan $\mathrm{Pe}_{2}$ sebesar 0,28. Hasil koefisien determinasi total sebesar 0,993 mempunyai arti bahwa sebesar 99,3\% variasi efektivitas tim dipengaruhi oleh variasi kecerdasan emosional dan kepemimpinan transformasional, sedangkan sisanya sebesar $0,7 \%$ dijelaskan oleh faktor lain yang tidak dimasukkan ke dalam model.

Tabel 19.

Pengaruh Langsung dan Pengaruh Tidak Langsung serta Pengaruh Total Kecerdasan Emosional (X), Kepemimpinan Transformasional (M), dan Efektivitas Tim (Y)

\begin{tabular}{cccc}
\hline $\begin{array}{c}\text { Pengaruh } \\
\text { Variabel }\end{array}$ & $\begin{array}{c}\text { Pengaruh } \\
\text { Langsung }\end{array}$ & $\begin{array}{c}\text { Pengaruh Tidak Langsung Melalui } \\
\text { Kepemimpinan Transformasional } \\
(\mathbf{M})(\boldsymbol{\beta 1} \mathbf{x} \boldsymbol{\beta 3})\end{array}$ & $\begin{array}{c}\text { Pengaruh } \\
\text { Total }\end{array}$ \\
\hline $\mathrm{X} \rightarrow \mathrm{M}$ & 0,830 & - & 0,830 \\
$\mathrm{X} \rightarrow \mathrm{Y}$ & 0,504 & 0,318 & 0,822 \\
$\mathrm{M} \rightarrow \mathrm{Y}$ & 0,383 & - & 0,383 \\
\hline
\end{tabular}

Sumber: Data primer diolah, 2018.

Tabel 19. menunjukan kecerdasan emosional memiliki pengaruh langsung terhadap kepemimpinan transformasional sebesar 0,830. Sebesar 0,503 adalah pengaruh langsung kecerdasan emosional terhadap efektivitas tim dan memiliki pengaruh tidak langsung melalui kepemimpinan transformasional sebesar 0,318 sehingga pengaruh totalnya sebesar 0,822 . Pengaruh langsung kepemimpinan transformasional terhadap efektivitas tim sebesar 0,383. 
Uji sobel dalam penelitian ini digunakan untuk menguji signifikansi dari hubungan tidak langsung antara variabel eksogen dengan variabel endogen yang dimediasi oleh variabel mediator.

$$
\mathrm{Z}=\frac{a b}{\sqrt{\mathrm{b}^{2} S_{\mathrm{a}}^{2}+\mathrm{a}^{2} \mathrm{~S}_{\mathrm{b}}^{2}+S_{\mathrm{a}}^{2} S_{\mathrm{b}}^{2}}}
$$

Keterangan:

$\mathrm{a}=0,83$

$\mathrm{s}_{\mathrm{a}}=0,062$

$\mathrm{b}=0,383$

$\mathrm{Sb}=0,113$

$$
\begin{aligned}
& Z=\frac{0,93.0,393}{\sqrt{(0,383)^{2}(0,062)^{2}+(0,83)^{2}(0,113)^{2}+(0,062)^{2}(0,113)^{2}}} \\
& Z=\frac{0,3179}{\sqrt{0,0006+0,0098+0,0000}} \\
& Z=\frac{0,3179}{\sqrt{0,0094}} \\
& Z=\frac{0,3163}{0,097003} \\
& Z=3,2771
\end{aligned}
$$

Bila nilai kalkulasi Z lebih besar dari 1,96 (dengan tingkat kepercayaan 95 persen), maka variabel mediator dinilai secara signifikan memediasi pengaruh variabel eksogen dan variabel endogen. Hasil tersebut dapat dilihat pada Tabel 20.

Tabel 20.

Hasil Uji Sobel

\begin{tabular}{ccc}
\hline No. & Nilai $\mathbf{Z}$ & Sig \\
\hline 1 & 3,2771 & 0,000
\end{tabular}

Sumber: Data Primer Diolah, 2018

Berdasarkan hasil uji sobel pada Tabel 20. menunjukkan bahwa hasil tabulasi $\mathrm{Z}=3,2771>1,96$ dengan tingkat signifikansi $0,000<0,05$ yang berarti variabel mediator yakni kepemimpinan transformasional dinilai secara signifikansi memediasi pengaruh antara kecerdasan emosional terhadap efektivitas tim.

Uji efek mediasi dilakukan untuk mengetahui peran variabel mediasi yang menghubungan antara variabel independen dengan variabel dependen. Pengujian 
peran kepemimpinan transformasional sebagai variabel mediasi dapat diketahui dari perhitungan nilai VAF pada masing-masing hubungan.

$$
\mathrm{VAF}=\frac{\mathrm{b} \times \mathrm{c}}{\mathrm{a}+\mathrm{b} \times \mathrm{c}}
$$

$$
\begin{aligned}
& \text { Keterangan : } \\
& \mathrm{a}=0,821 \\
& \mathrm{~b}=0,83 \\
& \mathrm{c}=0,383 \\
& \mathrm{VAF}=\frac{0,83 \times 0,38: 3}{0,821+0,83 \times 0,383} \\
& =\frac{0,31789}{1,13889} \\
& =0,28 \\
& =28 \text { persen }
\end{aligned}
$$

Perhitungan uji VAF didapatkan hasil sebesar 28\% yang berarti berada pada kisaran nilai antara $20 \%$ sampai $80 \%$, berarti variabel mediator yakni kepemimpinan transformasional dinilai memiliki peran sebagai pemediasi parsial antara kecerdasan emosional terhadap efektivitas tim.

Berdasarkan hasil pengujian hipotesis, pengaruh kecerdasan emosional dengan kepemimpinan transformasional dengan hasil Signifikansi 0,000 (kurang dari 0,05 ) serta koefisien beta sebesar 0,830 yang menunjukkan bahwa kecerdasan emosional berpengaruh positif dan signifikan terhadap kepemimpinan transformasional. Hasil ini memiliki arti bahwa jika semakin tinggi tingkat kecerdasan emosional yang dimiliki pemimpin PT. Surticon Buana Perkasa maka karyawan akan merasa bahwa pemimpinnya memiliki gaya kepemimpinan transformasional yang tinggi. Hasil penelitian ini sesuai dengan hasil penelitian sebelumnya.

Hasil pengujian memperoleh nilai koefisien beta sebesar 0,504 dengan tingkat signifikansi 0,000 kurang dari 0,05 , yang berarti variabel kecerdasan emosional berpengaruh positif dan signifikan terhadap efektivitas tim. Hasil ini memiliki arti bahwa semakin tinggi tingkat kecerdasan emosional karyawan PT. Surticon Buana Perkasa berarti semakin tinggi pula efektivitas tim kerja karyawan dalam perusahaannya. Hasil penelitian ini sesuai dengan hasil penelitian sebelumnya.

Hasil pengujian penelitian ini diperoleh nilai koefisien beta sebesar 0,383 dengan tingkat signifikansi 0,000 kurang dari 0,05, yang berarti variabel kepemimpinan transformasional berpengaruh positif dan signifikan terhadap efektivitas tim kerja. Hasil ini memiliki arti bahwa gaya kepemimpinan transformasional yang dimiliki pemimpin PT. Surticon Buana Perkasa akan 
membuat efektivitas tim kerja karyawan akan semakin meningkat. Hasil penelitian ini sesuai dengan penelitian sebelumnya

Hasil pengujian pada uji sobel menunjukkan nilai Z sebesar 3,2771 lebih dari 1,96 dengan tingkat nilai signifikansi 0,000 kurang dari 0,05 maka kepemimpinan transformasional secara positif dan signifikan memediasi pengaruh antara kecerdasan emosional terhadap efektivitas tim. Artinya semakin tinggi tingkat kecerdasan emosional seeorang, maka semakin tinggi pula kemampuannya untuk memimpin perusahan dan dengan demikian efektivitas tim kerja karyawan perusahaan akan semakin baik. Hasil dari penelitian ini telah sesuai dengan penelitian sebelumnya.

Hasil penelitian ini memiliki implikasi teoritis dan praktis. Implikasi teoritis, hasil penelitian ini menunjukan bahwa kecerdasan emosional berpenagruh positif dan signifikan terhadap efektivitas tim kerja melalui mediasi kepemimpinan transformasional. Hasil penelitian tersebut memberikan dukungan empiris untuk memperkuat hasil - hasil penelitian terdahulu. Diharapkan penelitian ini dapat menjadi suatu hal baru untuk penelitian yang berhubungan dengan variabel kecerdasan emosional, kepemimpinan transformasional dan efektivitas tim. Implikasi praktis, penelitian ini diharapkan dapat memberikan manfaat bagi pihak PT. Surticon Buana Perkasa. Penelitian ini mengandung implikasi agar pihak manajemen dan karyawan dapat meningkatkan efektivitas tim kerja dalam perusahaan guna mewujudkan tujuan perusahaan.

Terdapat keterbatasan yang mempengaruhi kondisi dari penelitian yang dilakukan. Adapun keterbatasan dalam penelitian ini yaitu. Jumlah responden hanya 52 orang karyawan dan hanya dari lingkungan PT. Surticon Buana Perkasa, sehingga hasil penelitian ini hanya dapat diterapkan dilingkungan kerja PT. Surticon Buana Perkasa dan tidak dapat digeneralisasi pada lingkungan perusahaan lain, faktor yang mempengaruhi efektivitas tim kerja karyawan pada penelitian ini hanya kecerdasan emosional dan kepemimpinan transformasional akan tetapi banyak faktor lain yang dapat digunakan oleh penelitian selanjutnya.

\section{SIMPULAN DAN SARAN}

Simpulan yang dapat diambil berdasarkan hasil analisis adalah sebagai berikut. Kecerdasan emosional berpengaruh positif dan signifikan terhadap efektivitas tim kerja, kecerdasan emosional berpengaruh positif dan signifikan terhadap kepemimpinan transformasional, Kepemimpinan transformasional berpengaruh positif dan signifikan terhadap efektivitas tim kerja, kecerdasan emosional berpengaruh positif dan signifikan terhadap efektivitas tim kerja melalui mediasi kepemimpinan transformasional.

Saran yang dapat diberikan, berdasarkan pada hasil analisis, pembahasan dan simpulan adalah sebagai berikut. Pimpinan harus dapat memberi pengertian untuk meningkatkan kemampuan berfikir karyawannya agar karyawan memiliki emosi diri yang stabil dalam mengerjakan suatu pekerjaan secara efektif, pihak perusahaan hendaknya dapat lebih rutin untuk mengadakan rapat dan karyawan sebaiknya lebih aktif untuk saling berkomunikasi, meningkatkan kemampuan pimpinan dalam mengajarkan pertimbangan individual kepada karyawan untuk dapat berkembang dan berprestasi dengan menjadi mentor yang memperhatikan 
persoalan-persoalan karyawannya, pihak perusahaan hendaknya dapat mempertahankan dan meningkatkan kecerdasan emosional masing-masing individu agar efektivitas tim kerja perusahaan dapat meningkat melalui gaya kempemimpinan transformasional yang baik.

\section{REFERENSI}

Alam, Shahram. (2014). The Relationship Between Emotional Intelligence and Transformational Leadership in Sports Managers. European Journal of Experimental Biology, 4(3), 352-356.

Bass, B. M. (1985). Leadership and Performance Beyond Expectation. New York: Free Press.

Darto, Mariman. (2013). Kepemimpinan Transformasional Dalam Konteks Perubahan Organisasi di Lembaga Administrasi Negara. Jurnal Borneo Administrator, 9(3), 240-264.

Dewi, Dimika Sari \& Ni Wayan Mujiati. (2015). Pengaruh The Big Five Personality dan Kepemimpinan Transformasional Terhadap Kinerja Karyawan di Karma Jimbaran Villa. E-Jurnal Manajemen Unud. 4(4), 930-942.

Esfahani, Nooshin \& Hamid Gheze Soflu. (2011). Relationship Between Emotional Intelligence and Transformasional Leadership in Physical Education Manager Procedia. Procedia - Sosial and Behavioral Sciences, 30(2), 2384-2393.

Estianda, Yarouf. (2014). Pengaruh Kepribadian dan Efektivitas Tim terhadap Organizational Citizenship Behavior (OCB) Pegawai di Badan Pendidikan dan Pelatihan Kementerian dalam Negeri. Jurnal Manajemen Pendidikan, 5(2), 917-926.

Fikrie, Mohd Anugrah. (2017). Pengaruh Kemampuan, Sikap dan Kecerdasan Emosional terhadap Efektivitas Kerja Pegawai Dinas Pariwisata dan Ekonomi Kreatif Provinsi Riau. JOM Fekon, 4(1), 694-708.

Ghozali, Imam. (2013). Aplikasi Analisis Multivariate dengan Program IBM SPSS21 Update PLS Regresi. Edisi ketujuh. Semarang: Badan Penerbit Universitas Diponogoro.

Goleman, D. (2015). Emotional Intelligence edisi terjemahan. Jakarta : PT Gramedia Pustaka Utama.

Gumusluoglu, L., \& Ilsev, A. (2009). Transformational leadership, creativity, and organizational innovation. Journal of Business Research, 62(1), 461-473.

Gunawan, Indra I Kadek \& I Gusti Salit Ketut Netra. (2017). Pengaruh Kepemimpinan Transformasional dan Komitmen Organisasional Terhadap 
Organizational Citizenship Behavior Karyawan. E-Jurnal Manajemen Unud, 6(4), 2133-2160.

Harminder, K,G \& Jaya, A. (2011). Impact of Emotional Intelligence on Teamwork - A Comparative Study of Self-managed and Cross Functional Teams. International Journal of Multidisciplinary Research, 1(6), 178185.

Hariandja, Evo dkk. (2007). Analisis Pengaruh Budaya, Komitmen Pemimpin dan Kecerdasan Emosional Anggota Terhadap Efektivitas Organisasi Pada PT. Mitsubishi Krama Yudha Motors \& Manufacturing. Jurnal Inovisi ${ }^{\mathrm{TM}}, 6(1)$, 45-57.

Heristi, Kartika D. \& Seger Handoyo. (2011). Hubungan antara Servant Leadership dengan Efektifitas Tim ditinjau dari Persepsi Anggota Tim PHKI-Jurusan di Institut Teknologi Sepuluh Nopember Surabaya. INSAN, 13(1), 58-63.

Jeevan, Jyoti Manisha Dev. (2015). The impact of transformational leadership on employee creativity: the role of learning orientation. Journal of Asia Business Studies, 9(1), 78 - 98.

Khan, Saqib et al. (2014). The Impact of Emotional Intelligence up on the Team. Research on Humanities and Social Sciences, 4(22), 1-7.

Kusnara. (2013). Pengaruh Komunikasi Interpersonal dan Kecerdasan Emosional Terhadap Efektivitas Kerja Guru di UPTD Pendidikan Kecamatan Cibingbin Kabupaten Kuningan. Jurnal Ilmiah Mahasiswa Pascasarjana Administrasi Pendidikan, 1(1), 99-106.

Lam, Cheok San \& Elenor O'Higgins. (2015). To Examine the Influence of Emotional Intelligence on Team Outcomes via the Mediating Mechanism of Transformational Leadership. Management and Organizational Studies, 2(1), 120-135.

Ljungholm, Doina Popescu. (2014). Transformational Leadership Behavior in Public Sector Organizations. Contemporary Readings in Law and Social Justice, 6(1), 76-81.

Lopez, Melvyn. (2015). Analyzing the Relationship Between Transformational Leadership Behavior and Team. Dissertation, Northcentral University.

McShane, S.L., \& Von Glinow, M.A. (2008). Organizational Behavior: Emerging Realities For The Workplace Revolution. 4th Edition. McGraw-Hill/Irwin.

Mula, David M. (2013). Examining Emotional Intelligence and Transformational Leadership within U.S. Army National Guard Leaders. Dissertation, Walden University. 
Murida, Ratna., Mukhlis Yunus \& Amri. (2013). Pengaruh Kepemimpinan, Kecerdasan Emosional dan Budaya Organisasi terhadap Kinerja Pegawai serta Dampaknya pada Kinerja Sekretariat Daerah Aceh. Jurnal Manajemen Pascasarjana Universitas Syiah Kuala, 2(1), 108-117.

Prati, L. M., Douglas, C., Ferris, G. R., Ammeter, A. P., \& Buckley, M. R.. (2003). Emotional intelligence, leadership effectiveness, and team outcomes. International Journal of Organizational Analysis, 11(1), 21-40.

Salovey \& Mayer. (2006). Emotional Intellegent,: Whay Can Matter More Than IQ, NY. Bantam Book.

Schlechter, Anton F. (2008). Leader emotional intelligence, transformational leadership, trust and team commitment: Testing a model within a team context. SA Journal of Industrial Psychology, 34(1), 42-53.

Sugiono. (2017). Metode Penelitian Bisnis. Jakarta: PT. Gramedia Pustaka Utama

Sultana, Umme Salma., Mohd Ridzuan Darun \& Liu Yao. (2015). Transactional or Transformational Leadership: Which Works Best For Now?. International Journal of Industrial Management (IJIM), 20(1), 1-9.

Tabassi, Amin Akhavan. (2013). Transformational Leadership and Team Effectiveness in the Construction Industry. Strategic Leadership Review, 3(4), 46-55.

Tantriana, I Gede Yogi. (2015). Pengaruh Kecerdasan Emosional dan Kepemimpinan Transformasional terhadap Kepuasan Kerja Karyawan di LPD Desa Adat Kerobokan. E-Jurnal Manajemen Unud, 4(8), 2269-2285.

Vierimaa , Joni Christian. (2013). Emotional Intelligence and Project Leadership An Explorative Study. Master of Science Thesis, Chalmers University of Technology.

Wageman, Ruth., J Richard Hackman \& Erin Lehman. (2005). Team Diagnostic Survey : Development of an Instrument. The Journal of Applied Behavioral Science, 41(4), 373-398.

Wahba, Mohamed. (2016). Transformational Leadership Impact on Team Performance and Conflict Applied Case Study on "Abi-Qir Company for Fertilizers”. International Journal of African and Asian Studies, 26(1), 119-126.

Yulk, G. (2006). Leadership in Organizations (6 ed.). New Jersey: Pearson Prentice Hall Inc.

Y. Hur, Peter Van den Berg, Celeste P.M. Wilderom. (2011). Transformasional Leadership as a Mediator Between Emotional Intelligence and Team Outcomes. The Leadership Quarterly, 22(1), 591-60. 
E-Jurnal Manajemen, Vol. 8, No. 8, 2019 :5202-5221

Zaccaro, S. J. (2001). The nature of executive leadership : A conceptual and empirical analysis of success. Washington, D.C. : American Psychological Association. 